\title{
Optimization of Rose Extraction Process by Orthogonal Design
}

\author{
Xin Zhang ${ }^{1}$, Dan Chen ${ }^{2 *}$, Xiao Cao ${ }^{1 *}$, Heng $\mathrm{Li}^{1}$, Limin $\mathrm{Wu}^{1}$ \\ ${ }^{1}$ Department of pharmacy, Fujian Vocational and Technical College of Bioengineering, Fuzhou 350003, \\ Fujian, China \\ ${ }^{2}$ School of Pharmacy, Fujian University of Traditional Chinese Medicine, Fuzhou 350005, Fujian, China \\ *Corresponding Author.
}

\begin{abstract}
:
To optimize the rose extraction process and evaluate the antioxidant properties of the extracts. The contents of gallic acid and rutin in rose extracts were used as indicators. According to the results of single-factor evaluation of the crushing degree of rose during extraction, extraction method, solid-liquid ratio of extraction and ethanol concentration. The three-factor and three-level L9 $\left(3^{3}\right)$ orthogonal design optimized extraction scheme was established. The factor levels were as follows: solid-liquid ratio (1:8, 1:10, 1:12); Ethanol concentration of extractant $(50 \%, 80 \%, 100 \%)$; Extraction method (ultrasonic treatment with ice for 30min, 3 times; Ultrasonic treatment with ice for $1 \mathrm{~h}$ and 3 times; Reflux in water bath for $1 \mathrm{~h}, 3$ times); The DPPH in vitro antioxidant test was applied to compare the antioxidant capacity of the optimized extract and rose water extract. The best extraction scheme of rose was as follows: the ratio of solid to liquid was 1:10, the concentration of ethanol was $80 \%$, and the extraction method was ultrasonic for 1 hour and repeated three times. In the antioxidant experiment, it can be found that the antioxidant capacity of the extract is significantly higher than that of the rose water extract. The optimized rose extract has a significantly higher antioxidant capacity than the rose water extract. The establishment of the extraction method significantly improves the utilization rate of antioxidant components in roses. It not only helps to improve the utilization rate of roses and avoids waste, but also helps the development and utilization of rose-related health products.
\end{abstract}

Keywords: Rose, Gallic acid, Rutin, Content, Extraction.

\section{INTRODUCTION}

Rose is the dried flower bud of Rosa rugosa Thunb., a plant in the Rose family [1]. It is native to China and now mainly distributed in China, Japan, Central Asia, Europe, Central America and other places. Wild rose populations can be found in mountainous areas, grasslands and coastal areas. However, the composition content of rose varies in different producing areas $[2,3]$. China have a long history of carrying roses. In the Han Dynasty, rose was considered to 
be able to get rid of filth and pestilence, and its transplanting and consumption were recorded $[4,5]$. In the Ming Dynasty, rose food was believed to have the function of "benefiting spleen and stomach, benefiting liver and gall, warding off evil spirits, eating fragrance and making people cool". The performance of its use as a drug is "mild but not fierce, soothing the liver and waking the stomach, ventilation and activating the blood" [6]. Modern pharmacological studies have found that rose can regulate endocrine, remove freckle, moisturize skin, regulate endocrine, inhibit bacteria, fight oxidation, improve immunity, fight cancer and reduce blood sugar [7-10].

At present, many achievements have been made in researches on rose around the world. It mainly focuses on the evaluation of volatile components of rose from different provenances and the extraction and utilization of rose essential oil. Bulgaria has the highest extraction rate of Damascus rose essential oil [11-14]. But the oil yield of Damascus oil rose introduced is not ideal. Its development and utilization is limited [15]. Essential oil ingredients are often present that do not readily store for a long time. Apart from the very low concentration of flower water, it is not easy to develop for other oral food. Rose is only used to extract essential oil and there is a lot of waste.

Internationally, roses are widely distributed and have many varieties. They are even suitable for saline-alkali cultivation [16]. But moet varieties are non-oil rose [13]. The rate of essential oil extraction is very low. There are many kinds of volatile components. However, the content of most essential oils is not high, and the waste of pure extraction essential oils is more serious and the market competitiveness is weak. Most of the roses in Korea can only be sold as scented tea, except for a few freshly processed foods with short shelf life and oil extraction. Because scented tea needs hot water to brew, it is inconvenient to take and carry. The utilization degree of antioxidant components is not high, the inefficient utilization of rose, the low added value and economic benefit of development result in the restriction of the development and utilization of domestic planted rose.

In recent years, the antioxidant capacity of rose and the development of functional food have attracted more and more attention [14-18]. Niu Shumin, Li Wei and others evaluated more than 40 kinds of Chinese medicinal materials and found that rose has the strongest antioxidant capacity [19]. Wang Gang and Yao Lei extracted total flavonoids from the rose and estimated 13 flavonoids with THE UPLC-Q-TOF-MS/MS technology [20]. Dariusz Nowak, Michal Goslinski, Elzbieta Wojtowicz et al. Determination of gallic acid in rose by HPLC. They rated it as having strong antioxidant capacity. It can be developed as an antioxidant functional drink [21]. 
Because at present only part of the components in rose extraction and antioxidant evaluation. Legal extraction may result in the loss of other antioxidants. The experimental design uses the traditional Chinese Shandong Pingyin rose. The contents of non-volatile antioxidant components rutin (main component of flavonoids) and gallic acid (main component of polyphenols) with the largest contents in rose extract [22-26] were taken as the main evaluation indexes. HPLC (high performance liquid chromatography) was used for determination. Orthogonal design was used after single factor evaluation screening. The extraction process was optimized and solvent recovery, concentration and antioxidant evaluation were carried out. Extraction of main antioxidant components from rose is beneficial to further development and application of rose germplasm resources in China. This will meet the needs of healthy functional food development in China, enhance the immunity of social groups, improve the resistance to COVID-19, and meet the needs of anti-cancer and blood sugar regulation.

\section{INSTRUMENT AND DRUG TEST}

\subsection{Instrument}

HPLC (Shimadzu, 2030C). COSMOSIL Column (5C18-MS-II, 4.6*250mm); Electric Unit Air Constant Temperature Drying oven (Model 101-2, Shanghai Dongxing Building Materials Reagent Equipment Co., LTD.); Ultrasonic cleaning machine (KQ-500B), Milli-Q Ultra Pure Water Equipment (Direct16, Millipore, USA). 1/100,000 analytical balance (CPA225D, Sartorius, Germany). Circulating water vacuum pump (Gongyi Yuhua Instrument Co., LTD.), model SHZ - DIII.T6 UV-visible spectrophotometer (Shanghai Electronic Instrument Co., LTD.). Sand core filter device. Vacuum pressure extraction and filtration device. Circulating water vacuum pump (model SHZ-DIII, Gongyi Yuhua Instrument Co., LTD.). Constant temperature water and oil bath (Model RE-501, Gongyi Yuhua Instrument Co., LTD.), Rotary evaporator (model RE-501, Gongyi Yuhua Instrument Co., LTD.), OLYMPUS SZ61 microscope (OLYMPUS Corporation, Japan).

\subsection{Try Drugs}

Sample: Shandong Pingyin rose bud (Jinan Tianyuan Rose Development Co., LTD.) in 2019.

Reference substance: Rutin 20771-100mg (Shanghai Yuanye Biotechnology Co., LTD.). Gallic acid B20851-200 mg (Shanghai Yuanye Biotechnology Co., LTD.). DPPH (1, 1-di-phenyl-2-Picryhydrazyl) reference substance. 
Reagent consumables: Phosphoric acid (Batch Number 10000218, Sinopharm Chemical Reagent Co., Ltd. Tianjin BasF Chemical Co., Ltd., China.) Chromatographic pure methanol (Merck \& Co., Ltd), hydrochloric acid (AR,2018070719, Sanming Sanyuan Chemical Reagent Co., Ltd), $0.45 \mu \mathrm{m}$ organic series microporous filter membrane, $0.45 \mu \mathrm{m}$ organic series filter head, disposable syringe filter and related glassware. Methanol (AR, Batch No: 20180716, Sinopharm Chemical Reagent Co., LTD.). Analysis of pure ethanol, chloral hydrate, pipette gun head, ear ball, funnel, beaker, medicine scoop, mobile phase flask, injection flask, volumetric flask, $0.45 \mu \mathrm{m}$ water, oil microporous membrane, $0.45 \mu \mathrm{m}$ water, oil filter head. etal. Zeolite. Drinking water.

\section{METHODS AND RESULTS}

\subsection{Solution Preparation}

\subsubsection{Preparation of reference solution}

Gallic acid was precisely weighed separately. $7.84 \mathrm{mg}$ and $8.16 \mathrm{mg}$ of rutin in $100 \mathrm{~mL}$ vial. It adds an $80 \%$ methanol solution. The concentrations of gallic acid and rutin were $0.0784 \mathrm{mg} /$ $\mathrm{mL}$ and $0.0816 \mathrm{mg} / \mathrm{mL}$, respectively.

\subsubsection{Negative reference solution}

It lacks rose extract, and the rest is prepared with test solution.

\subsubsection{Preparation of test solution}

The extracts obtained under the following different extraction conditions were filtered. The filtrate was filtered with 0.45 um microporous membrane, and obtained.

\subsubsection{Preparation of DPPH solution}

Accurately weigh DPPH reference substance in $9.9 \mathrm{mg}$ to $100 \mathrm{~mL}$ flask. Anhydrous ethanol was added to prepare DPPH anhydrous ethanol solution with a concentration of $0.25 \mathrm{mmol} / \mathrm{L}$.

\subsubsection{DPPH antioxidant experiment Preparation of rose water extract}

Take 19 year rose powder (pass through no. 3 sieve). Add boiling water to brew for $25 \mathrm{~min}$ 
and fill the weight. It made into $0.2 \%, 0.3 \%, 0.4 \%, 0.5 \%, 1.0 \%, 2.0 \%, 5.0 \%$ of the solution $[27$, 28].

\subsection{Determination Method and Results of Rutin and Gallic Acid in Rose Extract by HPLC}

The contents of gallic acid and flavonoids in the extract were determined by HPLC.COSMOSIL C18 column $(250 \mathrm{~mm} \times 4.6 \mathrm{~mm}, 5 \mu \mathrm{m})$. Gradient elution of mobile phase methanol-formic acid $(0.2 \%)$ was shown in Table I. The detection wavelength of gallic acid was $274 \mathrm{~nm}$. The detection wavelength of flavonoids was $254 \mathrm{~nm}$. The flow rate was $1.0 \mathrm{~mL} / \mathrm{min}$ and the column temperature was $30^{\circ} \mathrm{C}$. The separation of gallic acid, rutin, hyperin, isoquercetin, quercetin and quercetin peaks was good $\mathrm{R}>1.5$ under the specified chromatographic conditions. The number of theoretical plates should not be less than 3000 on gallic acid scale. HPLC figure of rose extract was shown in Fig 1.

Table I. Screening gradient elution method

\begin{tabular}{|c|c|c|}
\hline TIME & METHYL ALCOHOL (A) & $0.2 \%$ FORMIC ACID (D) \\
\hline $0-10 \mathrm{MIN}$ & $3 \%$ & $97 \%$ \\
\hline $10-15 \mathrm{MIN}$ & $3 \%-4 \%$ & $97 \%-96 \%$ \\
\hline $15-20 \mathrm{MIN}$ & $4 \%-40 \%$ & $96 \%-60 \%$ \\
\hline $20-55 \mathrm{MIN}$ & $40 \%-50 \%$ & $60 \%-50 \%$ \\
\hline $55-61 \mathrm{MIN}$ & $50 \%-55 \%$ & $50 \%-45 \%$ \\
\hline $61-71 \mathrm{MIN}$ & $55 \%$ & $45 \%$ \\
\hline $71-75 \mathrm{MIN}$ & $55 \%-3 \%$ & $45 \%-97 \%$ \\
\hline $75-85 \mathrm{MIN}$ & $3 \%$ & $97 \%$ \\
\hline
\end{tabular}

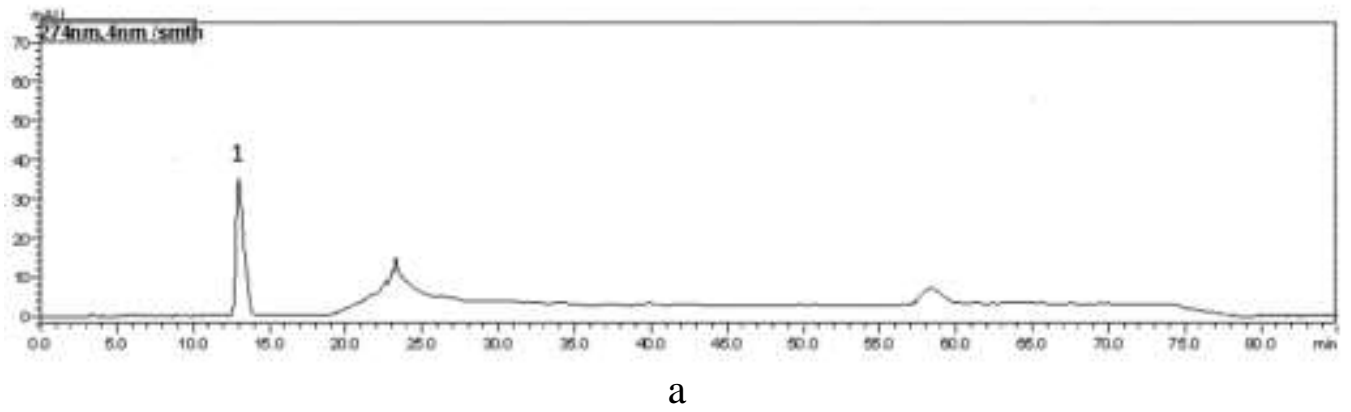





Fig 1: HPLC diagram of rose extract

Note: Label 1 is gallic acid peak and label 2 is rutin peak. Fig 1a shows the negative control HPLC figure. Fig $1 \mathrm{~b}$ is gallic acid reference HPLC diagram. Fig 1c is HPLC diagram of rutin reference substance. Fig $1 \mathrm{~d}$ is the HPLC diagram of $274 \mathrm{~nm}$ rose extract. Fig 1e is HPLC diagram of $254 \mathrm{~nm}$ rose extract.

\subsection{Single Factor Evaluation of Extraction Conditions of Rose}

\subsubsection{Influence of extraction method}

Select the same batch of rose powder from sifter number three. Solid-liquid ratio 1:10. The extraction agent used $80 \%$ ethanol. The extraction method is as follows. Ultrasound for $1 \mathrm{~h}$ and 
3 times without ice, Ultrasound $0.5 \mathrm{~h}$ and 3 times with ice, Ultrasound 1 hour and 3 times with ice, Water bath is reheated 1 hour and 3 times. Water bath reflow for $30 \mathrm{~min}$ and 3 times. The results showed that the extraction rate was the highest by adding ice ultrasonic 3 times and 1 hour each time. The results are shown in Fig 2.

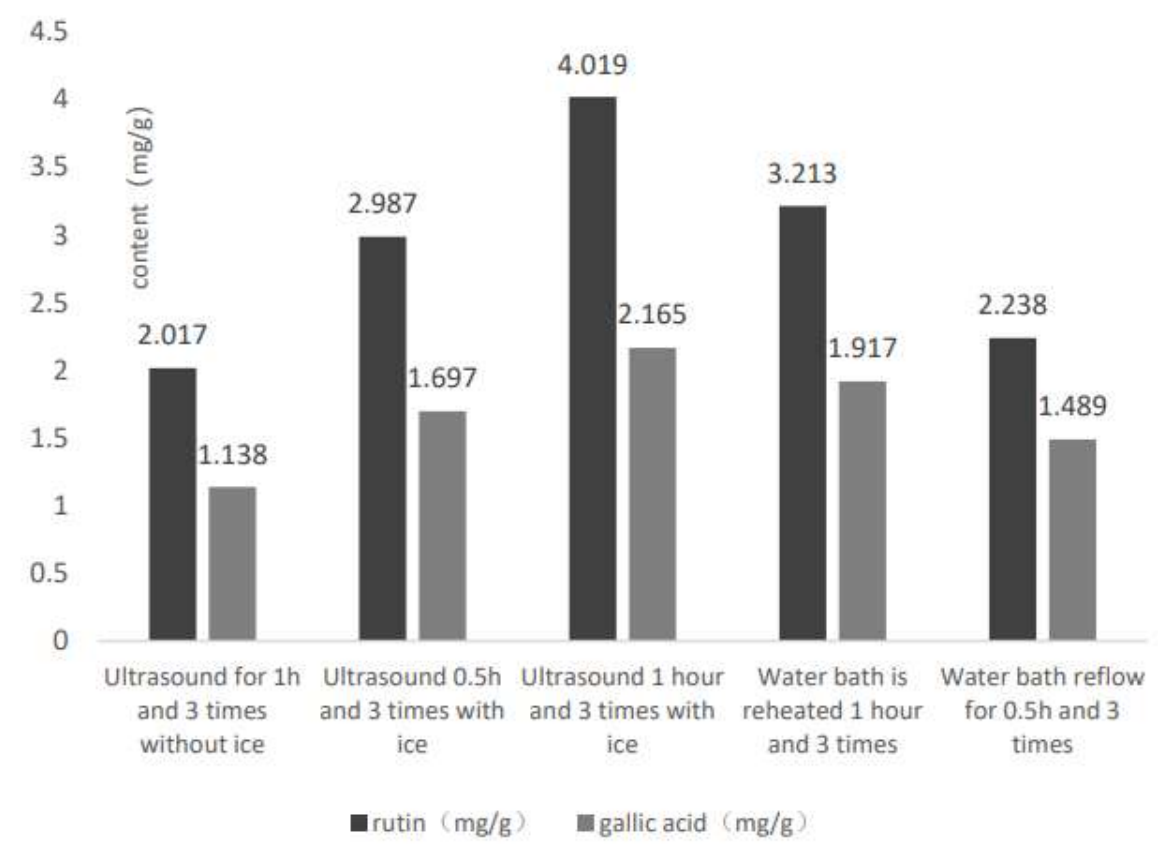

Fig 2: results of examining the effects of different extraction methods

\subsubsection{Effects of rose crushing degree on extraction}

The same batch of rose was selected to evaluate the influence of different degree of crushing on extraction. Selected degree of crushing. If not, beat the powder and pass through the sieve No.5 and No.3.The solvent was $80 \%$ ethanol. The ratio of extraction material to liquid was 1:10. The extraction method was ultrasound 3 times and $1 \mathrm{~h}$ each time with ice.

The results showed that the rutin and gallic acid contents were higher when rose powder was powdered and passed through no. 3 sieve. The results are shown in Fig 3. 


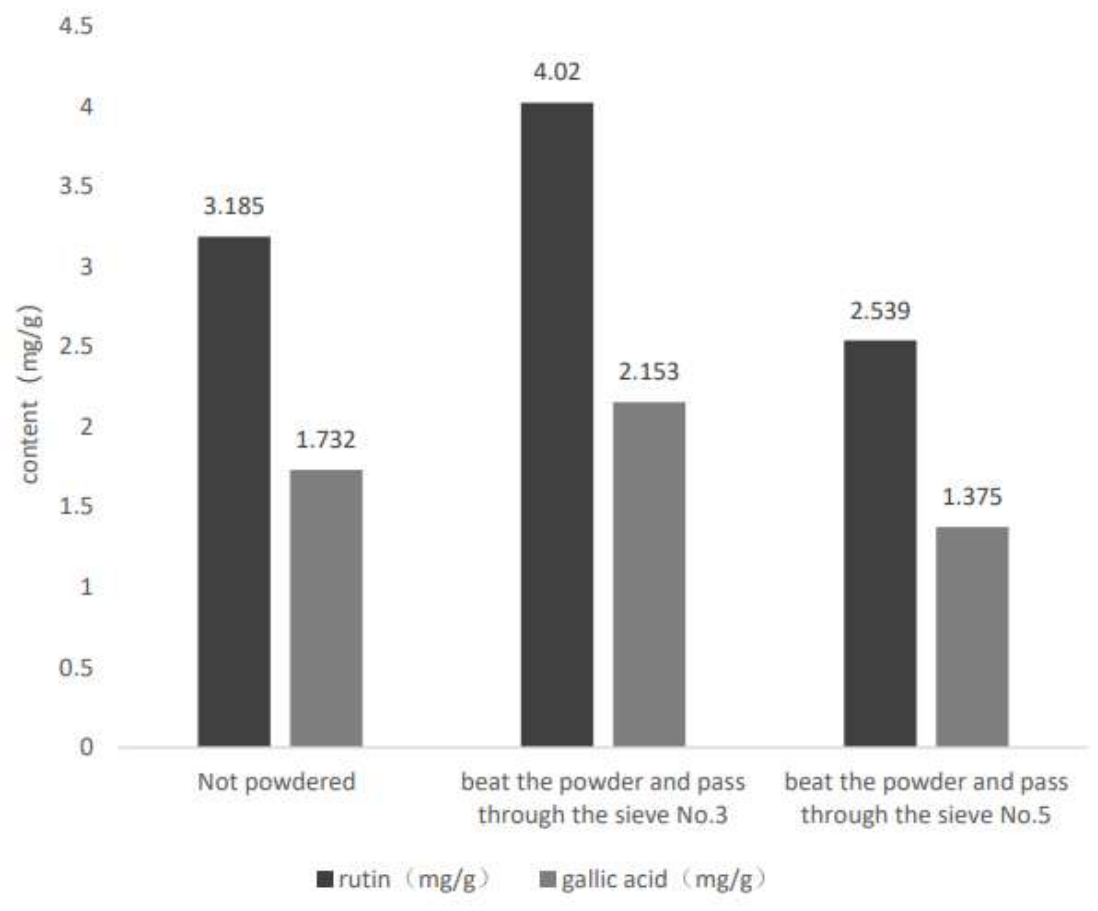

Fig 3: results of examining the effect of sample comminution on extraction

\subsubsection{Influence of extraction ratio of solid to liquid}

Select the same batch of rose powder from sifter number three. The extraction solvent was $80 \%$ ethanol. The extraction method was ultrasound 3 times and $1 \mathrm{~h}$ each time with ice. The ratio of material to liquid was $1: 12,1: 10,1: 8,1: 6$. The results showed that the extraction rate of rutin and gallic acid was the highest when the solid-liquid ratio was 1:10. The ratio of solid to liquid for rutin and gallic acid extraction was 1:8,1:10,1:12. The results are shown in Fig 4. 


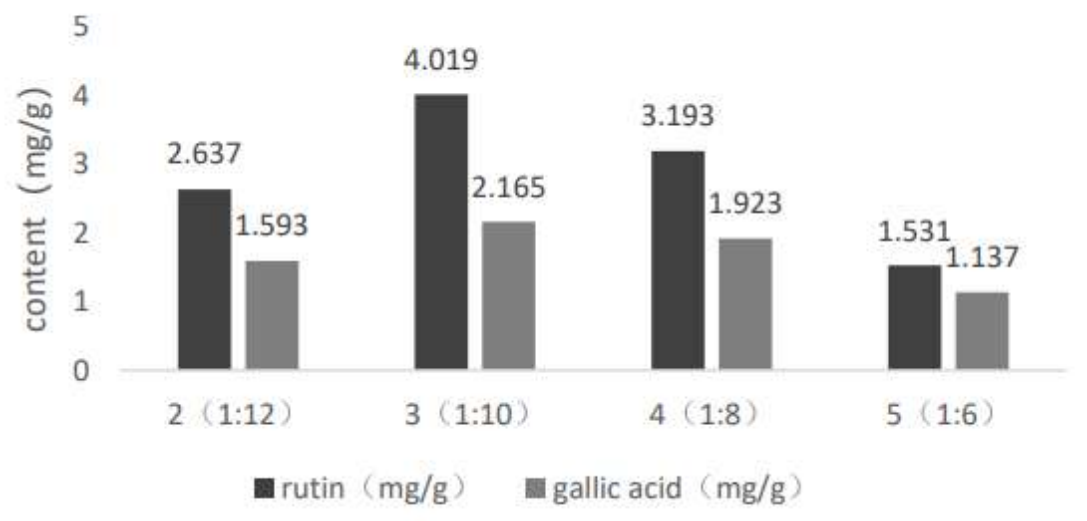

Fig 4: results of examining the effect of material-to-liquid ratio on extraction

\subsubsection{Influence of ethanol concentration of extraction agent}

Select the same batch of rose powder from sifter number three. The ratio of material to liquid is 1:10. The extraction method was ultrasound 3 times and $1 \mathrm{~h}$ each time with ice. Extraction agent ethanol concentration selected 10\%,30\%, 50\%, 80\%, 100\%. The results showed that the extraction rates of gallic acid and rutin were the highest when the ethanol concentration was $80 \%$. The results are shown in Fig 5.



Fig 5: results of examining the effect of different ethanol concentrations on extraction

\subsubsection{Results analysis}


After single factor investigation, three factors and three levels were screened out for further orthogonal experimental optimization design. It includes extraction ratio of material to liquid (1:8;"; 1:12), extraction agent ethanol concentration (50\%, 80\%, 100\%). Extraction method (ultrasound 30min with ice, 3 times; Ultrasound with ice for $1 \mathrm{~h}, 3$ times; Water bath reflux $1 \mathrm{~h}$, 3 times).

\subsection{Optimization of Orthogonal Experimental Design for Rose Extraction}

According to the results of single factor evaluation, the ratio of solid to liquid was selected. L9 $\left(3^{3}\right)$ was used for orthogonal experimental design of ethanol concentration and extraction method. Factors and levels are shown in Table II. The contents of gallic acid and rutin were calculated by external standard method. The orthogonal experimental design and results were shown in Table III. IBM SPSS Statistics Chinese version was used to analyze the results. The experimental results show that the three factors all have significant influence. The influence of three factors on extraction was as follows: blind liquid ratio > ethanol concentration > extraction method. Among them, the first factor has the most significant effect on the experimental results. The optimal solid-liquid ratio is 1:10. The results are shown in Table IV.

In summary, the liquid phase analysis conditions showed clear separation of each component and $\mathrm{R}>1.5$. This can meet the need of extract content determination. The extraction scheme was optimized by single factor analysis and orthogonal experiment design. The optimal extraction method of rose was $80 \%$ ethanol and the ratio of solid to liquid was 1:10. The extraction method was to add ice ultrasound for 1 hour and repeat three times.

Table II. Factor levels for orthogonal experiments on rose extracts

\begin{tabular}{|l|l|l|l|}
\hline & FACTOR & \\
\hline LEVEL & $\begin{array}{l}\text { SOLID-LIQUID } \\
\text { RATIO }\end{array}$ & $\begin{array}{l}\text { ETHANOL } \\
\text { CONCENTRATION }\end{array}$ & EXTRACTION METHOD \\
\hline 1 & $1: 8$ & $50 \%$ & $\begin{array}{l}\text { Ultrasound 0.5h with ice, 3 } \\
\text { times }\end{array}$ \\
\hline 2 & $1: 10$ & $80 \%$ & $\begin{array}{l}\text { Ultrasound with ice for 1h, 3 } \\
\text { times }\end{array}$ \\
\hline 3 & $1: 12$ & $100 \%$ & Reflux for 1h, 3 times \\
\hline
\end{tabular}

Table III. Results of orthogonal experiments on rose extraction process

\begin{tabular}{|c|c|c|}
\hline $\mathrm{NO}$ & 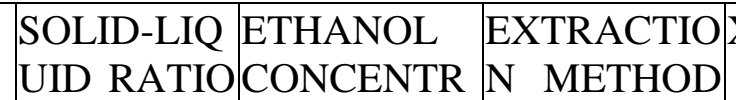 & \begin{tabular}{l|l|l} 
RUTIN & GALLIC & T \\
CONTENT & ACID $(M$ & L
\end{tabular} \\
\hline
\end{tabular}




\begin{tabular}{|l|l|l|l|l|l|l|l|}
\hline & (A) & ATION $(\mathrm{B})$ & (C) & & (MG/G) & G/G) & \\
\hline 1 & 1 & 1 & 1 & 1 & 0.318 & 0.398 & 0.716 \\
\hline 2 & 1 & 2 & 2 & 2 & 3.224 & 1.933 & 5.157 \\
\hline 3 & 1 & 3 & 3 & 3 & 0.345 & 0.414 & 0.759 \\
\hline 4 & 2 & 1 & 2 & 3 & 3.267 & 1.987 & 5.254 \\
\hline 5 & 2 & 2 & 3 & 1 & 3.233 & 1.928 & 5.161 \\
\hline 6 & 2 & 3 & 1 & 2 & 1.824 & 0.903 & 2.727 \\
\hline 7 & 3 & 1 & 3 & 2 & 0.618 & 0.642 & 1.260 \\
\hline 8 & 3 & 2 & 1 & 3 & 1.832 & 0.801 & 2.633 \\
\hline 9 & 3 & 3 & 2 & 1 & 1.581 & 0.701 & 2.282 \\
\hline AVERAGE 1 & 2.211 & 2.410 & 2.025 & 2.720 & & & \\
\hline AVERAGE 2 & 4.381 & 4.317 & 4.231 & 3.048 & & & \\
\hline AVERAGE 3 & 2.058 & 1.923 & 2.393 & 2.882 & & & \\
\hline RANGE & 2.323 & 2.394 & 2.206 & 0.328 & & & \\
\hline
\end{tabular}

Table IV. Analysis of orthogonal experimental results

\begin{tabular}{|c|c|c|c|c|c|}
\hline SOURCE & $\begin{array}{l}\text { MODEL } \\
\text { SQUARE SUM }\end{array}$ & IIIDF & $\begin{array}{l}\text { MEAN } \\
\text { SQUARE }\end{array}$ & $\mathrm{F}$ & $P$ \\
\hline $\begin{array}{l}\text { CORRECTION } \\
\text { MODEL }\end{array}$ & $28.110 \mathrm{a}$ & 6 & 4.685 & 57.942 & 0.017 \\
\hline INTERCEPT & 74.817 & 1 & 74.817 & 925.315 & 0.001 \\
\hline $\mathrm{A}$ & 10.125 & 2 & 5.063 & 62.614 & 0.016 \\
\hline$B$ & 9.607 & 2 & 4.803 & 59.408 & 0.017 \\
\hline C & 8.377 & 2 & 4.189 & 51.805 & 0.019 \\
\hline ERROR & .162 & 2 & 0.081 & & \\
\hline TOTAL & 103.088 & 9 & & & \\
\hline $\begin{array}{ll}\text { TOTAL OF } \\
\text { CORRECTION }\end{array}$ & $\mathrm{F} 28.271$ & 8 & & & \\
\hline
\end{tabular}

\subsection{Extraction Validation Experiment}

In order to investigate the stability of the above optimized extraction method, 3 rose samples were taken respectively. The validation experiment was carried out according to the 
optimal extraction process method. Rose extraction method is as follows. Take the herbs of pingyin rose, pulverize and pass through sieve number three. Dried gold at $80{ }^{\circ} \mathrm{C}$ for 3 hours and accurately weighed $5 \mathrm{~g}$ in conical flask. Add 50ml80\% ethanol and weigh. Ultrasound 3 times with ice and 1 hour each time. It is then extracted to wipe the walls of the bottle and made up with $80 \%$ ethanol.

The results showed that the contents of rutin and gallic acid in the extract were determined by HPLC. The measured rutin content was $4.063 \mathrm{mg} / \mathrm{g}, 4.019 \mathrm{mg} / \mathrm{g}, 4.005 \mathrm{mg} / \mathrm{g}$, the average content was $4.029 \mathrm{mg} / \mathrm{g}$, RSD was $0.61 \%(\mathrm{n}=3)$. Gallic acid contents were $2.137 \mathrm{mg} / \mathrm{g}$, $2.166 \mathrm{mg} / \mathrm{g}$ and $2.182 \mathrm{mg} / \mathrm{g}$ respectively. The average content was $2.162 \mathrm{mg} / \mathrm{g}$ with RSD of $0.86 \%(\mathrm{n}=3)$. The results suggested that the optimized extraction method was stable and reproducible.

\subsection{Microscopic Examination Difference Before and after Extraction}

Take a small amount of sepals and dried rose bud powder (through no. 2 sieve) and place them on a slide. Add a drop of chloral hydrate and place it on an alcohol lamp for slight permeation. Cover with cover glass. Use absorbent paper to carefully remove water stains that have spilled over the cover glass. Placed under a microscope for detection. Adjust from low resolution eyepiece to high resolution $(\times 100)$ eyepiece.

Check with a light microscope magnified 100 times. Sepals surface: non-glandular hairs dense, unicellular, much curved, 136-680 $\mu \mathrm{m}$ long, wall thick, woody. Glandular hair head multicellular, flat autumn, 64 -- $180 \mu \mathrm{m}$ in diameter, petiole multicellular, polyclonal, 50 -$340 \mu \mathrm{m}$ long. Single celled branches are sometimes seen at the base. Calcium oxalate cluster crystal diameter $9-25 \mu \mathrm{m}$. All meet the requirements of rose identification in 2015 edition of Chinese Pharmacopoeia.

After extraction, the same method was used to check no obvious tissue structure detected before extraction. It indicates that the drug has been extracted by ultrasound and has been released from the primary cells and tissues as much as possible. The structure before extraction has been damaged. It can no longer detect pre-extraction microscopic features.

\subsection{Concentration of Extract}

Add $50 \mathrm{~g}$ sample to $500 \mathrm{ml} 80 \%$ ethanol, extract for three times, and extract and filter. Mix the extract well and take $500 \mathrm{ml}$ each time. Using rotary evaporator, water bath $60{ }^{\circ} \mathrm{C}$ heating. Condense by rotary steaming to $100 \mathrm{ml}$. Merge three concentrates. Further concentrate to $50 \mathrm{ml}$. 
That is, the final concentration of $50 \mathrm{~g}$ sample extract is $50 \mathrm{ml}$. The density of the sample (alcohol aqueous solution) at $20{ }^{\circ} \mathrm{C}$ was measured by density bottle method. The volume fraction of ethanol content at $20^{\circ} \mathrm{C}$ is obtained by referring to the table.

To investigate the stability of the concentration method, three batches of samples were verified. The process of extraction and concentration was stable. High concentration efficiency and no explosion boiling occurred. According to the density bottle method, the alcohol content of the three batches of samples was less than $1 \%$. The experimental results show that the method is stable and reproducible.

\subsection{Comparison of Antioxidant Activity between Alcohol Extract and Water Extract}

\subsubsection{Preparation of rose alcohol extract optimized by DPPH antioxidant experiment}

The optimized rose alcohol extract was obtained. Based on the proportion of rose solids contained in the concentrate ( $1 \mathrm{~g}$ concentrate is equivalent to $1 \mathrm{~g}$ dried rose buds). Dissolve directly in water at $37 \pm 1{ }^{\circ} \mathrm{C}$. A series of optimized concentrated rose extracts with the same solubility as rose water extracts were prepared for test.

DPPH solution and rose water extract were prepared according to methods 3.1.3 and 3.1.4.

\subsubsection{Experimental process}

$2 \mathrm{~mL}$ samples of different concentrations were mixed with $2 \mathrm{~mL}$ DPPH solution. The reaction time was 30 min under dark condition. The absorbance value of the experimental group A was measured at $517 \mathrm{~nm}$. The absorbance value $A_{0}$ was measured by mixing ethanol and test solution as the experimental control group. The mixture of deionized water and DPPH was used as blank solution to measure the absorbance $A_{1}$. The absorbance of deionized water was eliminated before determination. The value of $A_{1}$ was 1.179 .

According to reference [29-31], the following formula was used to calculate the scavenging capacity of DPPH free radical:

DPPH free radical scavenging rate $\mathrm{SR}(\%)=\left[1-\left(\mathrm{A}-\mathrm{A}_{0}\right) / \mathrm{A}_{1}\right] \times 100 \%$

$\mathrm{A}_{0}$ is the control group mixed with ethanol and test solution. $\mathrm{A}_{1}$ is the control group mixed with deionized water and DPPH ethanol solution. A is the absorbance value of the experimental group. The experimental results showed that the antioxidant activity of effervescent tablets with 
the same concentration of dried rose buds was significantly higher than that of rose decoction. The clearance rate of rose effervescent tablets and rose decoction increased significantly when the concentration was about $1.0 \%-2.0 \%$, and then increased steadily. The clearance rate of rose effervescent tablet was up to $95.00 \%$. It had better scavenging effect on DPPH free radical and showed strong antioxidant ability. The results are shown in Table V and Fig 6.

Table V. Results of DPPH removal by samples

\begin{tabular}{|c|c|c|c|c|c|c|}
\hline & \multicolumn{3}{|c|}{$\begin{array}{l}\text { ROSE } \\
\text { DECOCTION }\end{array}$} & \multicolumn{3}{|c|}{$\begin{array}{l}\text { ROSE ALCOHOL EXTRACT } \\
\text { AFTER OPTIMIZATION }\end{array}$} \\
\hline $\begin{array}{|ll|}\text { MEASURED } \\
\text { BY r ROSE } \\
\text { CONCENTRAT } \\
\text { ION } / \%\end{array}$ & A & $\mathrm{A}_{0}$ & $\begin{array}{l}\text { CLEARANC } \\
\text { E RATE /\% }\end{array}$ & A & $\mathrm{A}_{0}$ & $\begin{array}{l}\text { CLEARANCE } \\
\text { RATE } / \%\end{array}$ \\
\hline 0.2 & 0.637 & 0.019 & $47.58 \%$ & 0.441 & 0.008 & $63.27 \%$ \\
\hline 0.3 & 0.531 & 0.023 & $56.91 \%$ & 0.316 & 0.012 & $74.21 \%$ \\
\hline 0.4 & 0.497 & 0.031 & $60.47 \%$ & 0.289 & 0.022 & $77.35 \%$ \\
\hline 0.5 & 0.483 & 0.039 & $62.34 \%$ & 0.235 & 0.03 & $82.61 \%$ \\
\hline 1 & 0.469 & 0.063 & $65.56 \%$ & 0.229 & 0.077 & $87.11 \%$ \\
\hline 2 & 0.539 & 0.141 & $66.24 \%$ & 0.313 & 0.199 & $90.33 \%$ \\
\hline 5 & 0.843 & 0.457 & $67.26 \%$ & 0.693 & 0.613 & $93.21 \%$ \\
\hline
\end{tabular}

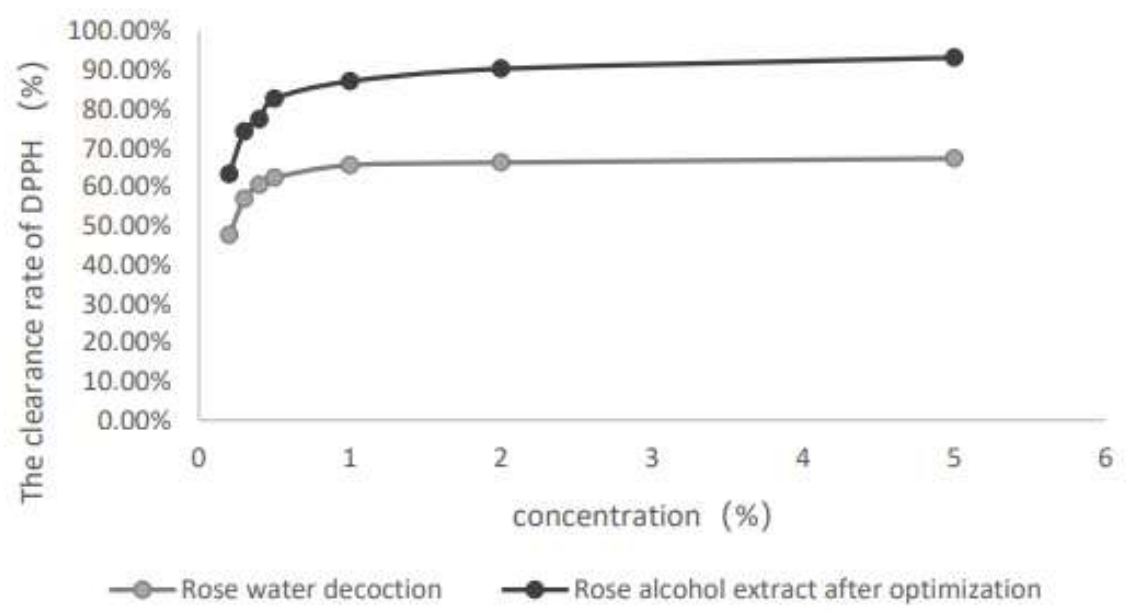

Fig 6: the clearance rate of DPPH by the optimized rose ethanol extract and rose water extract 


\section{DISCUSSION}

It considers the safety of rose preparations. The extraction solvent was ethanol. It was found that the extraction rates of gallic acid and rutin were similar between methanol and ethanol at the same solid-liquid ratio. Therefore, ethanol was selected as the extraction agent.

After single factor evaluation of extraction conditions and orthogonal experimental design. Single factor evaluation showed that the extraction rate of powdered rose increased than that of unpowdered rose. But the powder is too fine to filter clog the filter paper. This affects the extraction efficiency and significantly reduces the content measurement. So the sample is treated as powder through the second sieve. The optimal extraction conditions were $80 \%$ ethanol, solid-liquid ratio 1:10, ultrasonic $1 \mathrm{~h}$, repeated three times.

When the solid-liquid ratio was 1:10, the extraction rate of p-gallic acid and rutin was higher than 1:50. Considering the solid-liquid ratio of 1:50, the solid-liquid ratio of 1:50 is still in the linear range.

There is no precipitation in the sample at room temperature after rotary evaporation concentration. A small amount of precipitation precipitates after refrigeration. It may be a polysaccharide component. According to literature research, polysaccharide components also have antioxidant effects [28, 29], so removal and further concentration are not considered.

After experimental investigation, zeolite of different sizes should be added into the solution before rotary evaporation concentration. Otherwise, because of high alcohol concentration, extremely explosive boiling. The rotary steam temperature is only about $30{ }^{\circ} \mathrm{C}$, and the rotary steam efficiency is very low. After adding zeolite, the rotary steam temperature can be adjusted to about $60{ }^{\circ} \mathrm{C}$ and the efficiency is greatly improved. In the process of rotary steaming, it is necessary to intermittently open the exhaust port exhaust tension to avoid bursting boiling.

Rose water extract was boiled for $25 \mathrm{~min}$. The selection of water extraction method is referred to $[32,33]$. The extraction of polyphenols and flavonoids from rose and the antioxidant activity of the extraction were considered. It is more antioxidant than rose alcohol extract diluted in the same proportion. It was found that the antioxidant activity of the optimized rose alcohol extract was significantly higher than that of rose water decoction.

\section{CONCLUSION}

The contents of two representative antioxidant components in rose and. The optimized 
extraction conditions of rose were $80 \%$ ethanol and 1:10 solid-liquid ratio. The extraction method was to add ice ultrasound for 1 hour and repeat three times. The contents of gallic acid and rutin, two main antioxidant components in rose, could be significantly increased by this method. The DPPH antioxidant capacity of the extract prepared by the optimized method is significantly higher than that of the rose water extract. It can be explained that the content of antioxidant components in the rose extract prepared by this method is higher than that of directly brewing rose tea. The establishment of the extraction method is beneficial to expand the utilization of rose germplasm resources, promote the development of rose-related health products, and significantly improve the utilization rate of antioxidant components in rose.

\section{ACKNOWLEDGEMENT}

[Fund Project] National Science and Technology Project for Social Welfare Project Filing (2020L3018); Fujian Vocational College of Bio-engineering Project "Diabetes Health Management and Conservation Research" (2020ZD01); Fujian Education Fund Project "Preliminary Research on the Development of Rose Effervescent Tablets" (Project No.: JAT171016); Fujian health product research and testing platform (PT201706).

\section{REFERENCE}

[1] National Pharmacopoeia Commission (2020) Pharmacopoeia of the People's Republic of China. A. Beijing. Chemical Industry Press:209.

[2] Jiang LY (2018) Germplasm resources evaluation and core germplasm construction of endangered plant Rose. Shandong Agricultural University.

[3] Cai F (2008) Identification of Rose germplasm resources and Medicinal materials. Institute of Medicinal Plant. Peking Union Medical College.

[4] Southeast (2017) Research on the development strategy of pingyin Rose industry. Beijing University of Chemical Technology.

[5] Feng LG (2007) Evaluation of wild germplasm resources and genetic relationship with cultivated germplasm of Rose. Shandong Agricultural University.

[6] Wang YC (2016) Identification of aroma components in water and establishment of fingerprint of Chinese rose. Gan Su Agricultural University.

[7] Zhang W, Wang C, Zhang J, et al (2016) Research Progress of edible rose. Wild plant resources of China. 35(3):24-30.

[8] Tong Z (2017) Study on components, antibacterial and antioxidant capacity and stability of Essential oil from Rose of Zhejiang. Zhejiang Gongshang University.

[9] Song YR, Lim WC, Han A, et al (2020) Rose Petal Extract (Rosa gallica) Exerts Skin Whitening and Anti-Skin Wrinkle Effects. J Med Food 23(8):870-878.

[10] Inés M, Cristina S, Nerea JM, et al (2017) Therapeutic Applications of Rose Hips from Different Rosa Species. Int J Mol Sci. 18(6):1137. 
[11] Wang WL, Wang XL (2019) Study on chemical Constituents of essential Oil of Rose damascene from Different habitats. China tests 2019(3):59-64.

[12] Li YD, Liu XM, Qiu JW (2019) Comparison and analysis of essential oil components of Rose Damask from Different habitats. China Food Additives (7):64-72.

[13] Li TC, Hou DY, Hui RH, et al (2018) Comparative analysis of Volatile Components between fresh and dry rose. Journal of Anshan Normal University 20(4):22-25.

[14] Li KH (2019) Development of Rose industry in Bulgaria and relevant suggestions. World agriculture 09:131-134

[15] Maike. (2013) Classification and evaluation of oil rose germplasm resources based on genetic diversity in China. Shanghai Jiaotong University.

[16] Chen YR (2016) Comparison of aroma components and influencing factors among edible rose cultivars cultured in Yongdeng County. Gansu Agricultural University.

[17] Soraya S, Roodabeh B, Amin I, et al (2020) Advances on Natural Polyphenols as Anticancer Agents for Skin Cancer. Pharmacol Res 151:104584.

[18] Aleksashina SA, Makarova NV, Demenina LG (2019) Antioxidant potential of wild rose. Vopr Pitan 88(3):84-89.

[19] Niu SM, Li W, Li L (2006) Isolation, identification and activity determination of two antioxidant compounds from Rose. Journal of Nankai University (Natural Science edition) (1): 92-96 + 114 .

[20] Wang G, Yao L, Li ZJ (2019) Feasibility analysis of extraction of total flavones from rose residue of Bitter water. Shanghai Agricultural Science and Technology (2):35-37.45.

[21] Nowak D, Gośliński M, Wojtowicz E, et al (2018) Antioxidant Properties and Phenolic Compounds of Vitamin C-Rich Juices. Food Sci 83(8):2237-2246.

[22] Chen JY (2019) Four kinds of rose therapeutic recipes and their effects. Cooking Knowledge (3).

[23] Ma YH, Ma RL, Zheng L, et al (2018) Structural characteristics and antioxidant activity of polysaccharides from the receptorum of Rose Pingyin. Science and Technology of Food Industry 39(08):67-72.

[24] Chen XN, Li D (2018) Study on the development of rose industry in Pingyin. Research on Shandong economic Strategy (08):62-63.

[25] Liu WY (2018) Study on chemical Constituents and Antioxidant and Tyrosinase Inhibition activity of Rose residue. Zhengzhou University.

[26] Cheng SY (2017) Preparation and Properties of soft Myrrh fruit Spray Drying Juice Powder. Jilin University.

[27] Amaya-Cruz D, Peréz-Ramírez IF, Pérez-Jiménez J, et al (2019) Compari-son of the bioactive potential of Roselle (Hibiscus sabdariffa L.) ca-lyx and its by-product: Phenolic characterization by UPLC-QTOF MSE and their anti-obesity effect in vivo. Food Research Interna-tional 126:108589.

[28] Chen ZH (2012) Study on tea brewing method and polyphenols, caffeine and antioxidant activity. Tianjin University of Science and Technology.

[29] Agigu A, Chu GH, Anerbanjiang A, et al (2012) Fingerprint analysis of Uyghur Medicine Rose oral liquid by TLC. Journal of kashgar normal university 33(6):49-51.

[30] Jolanta F, Michał F (2020) The [DPPH•/DPPH-H]-HPLC-DAD Method on Tracking the Antioxidant Activity of Pure Antioxidants and Goutweed (Aegopodium podagraria L.) Hydroalcoholic Extracts. Molecules 25(24):6005. 
[31] Kandi S, Charles AL (2019) Statistical comparative study between the conventional DPPH spectrophotometric and dropping DPPH analytical method without spectrophotometer: Evaluation for the advancement of antioxidant activity analysis. Food Chem 287:338-345.

[32] Tumbas VT, Canadanović-Brunet JM, Cetojević-Simin DD, et al (2012) Effect of rosehip (Rosa canina L.) phytochemicals on stable free radicals and human cancer cells. J Sci Food Agric. 92(6):1273-81.

[33] Chen DM (2014) Ultrasonic extraction of polyphenols and polysaccharides from rose residue. Zhengzhou University. 